\title{
Das Zeitalter von Herbert Giersch
}

\author{
Wirtschaftspolitik für eine offene Welt \\ Hrsg. v. Lars P. Feld, Karen I. Horn u. Karl-Heinz Paqué
}

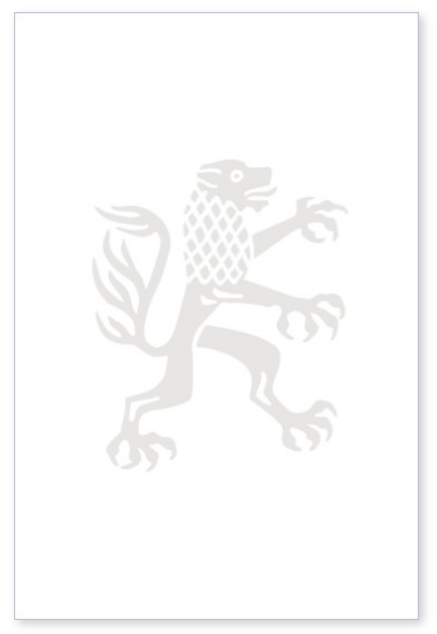

2013. XXI, 305 Seiten. UOrd 64

ISBN 978-3-16-152730-2

DOI 10.1628/978-3-16-152730-2

eBook PDF $74,00 €$

ISBN 978-3-16-151044-1

fadengeheftete Broschur 74,00€
Am 11. Mai 2011 wäre Herbert Giersch 90 Jahre alt geworden. Er lehrte von 1955 bis 1969 an der Universität des Saarlandes und von 1969 bis zu seiner Emeritierung 1989 als Präsident des Instituts für Weltwirtschaft an der Universität Kiel. Zudem war Giersch Gründungsmitglied des Sachverständigenrats zur Begutachtung der gesamtwirtschaftlichen Entwicklung. Der vorliegende Band enthält die Beiträge einer Tagung, die zu seinen Ehren in Freiburg veranstaltet wurde. Die Autoren beleuchten Gierschs wissenschaftliches Werk aus unterschiedlichen Perspektiven, seine Vorstellung von wirtschaftspolitischer Beratung, seine Analysen zu Konjunkturpolitik und Globalsteuerung, zur Angebotspolitik, zu Wachstum und weltwirtschaftlicher Entwicklung, zu Monetarismus und Wechselkursen, zum Strukturwandel, zur Regionalökonomik und zur Ordnungspolitik. Die Beiträge fassen nicht nur Gierschs Einsichten zu diesen Themen zusammen, sondern zeigen auch ihre Relevanz für die heutige Wirtschaftspolitik im Zeichen der Finanz- und Schuldenkrise auf. Zu den Autoren gehören eine Reihe von namhaften Ökonomen, darunter Peter Bernholz, Jagdish Bhagwati, Johannes Bröcker, Juergen B. Donges, Gerhard Fels, Bertram Schefold, Gerhard Schwödiauer, Hans-Werner Sinn, Manfred Streit, Roland Vaubel und Carl-Christian von Weizsäcker.

Lars P. Feld Geboren 1966; Studium der Volkswirtschaftslehre; 1999 Promotion; 2002 Habilitation; seit 2010 Direktor des Walter Eucken Instituts Freiburg, Inhaber des Lehrstuhls für Wirtschaftspolitik und Ordnungsökonomik an der Albert-LudwigsUniversität Freiburg und Mitglied des Sachverständigenrates zur Begutachtung der gesamtwirtschaftlichen Entwicklung.

Karen I. Horn Keine aktuellen Daten verfügbar.

Karl-Heinz Paqué Geboren 1956; Studium der Volkswirtschaftslehre in Saarbrücken, Kiel und Vancouver/Kanada; $1991-96$ Abteilungsleiter der Forschungsabteilung I (Wachstum, Strukturwandel und internationale Arbeitsteilung) des Instituts für Weltwirtschaft, Kiel; seit 1996 Professor für Volkswirtschaftslehre, insbesondere Internationale Wirtschaft an der Otto-vonGuericke-Universität Magdeburg.

Herbert Giersch Keine aktuellen Daten verfügbar.

Jetzt bestellen:

https://mohrsiebeck.com/buch/das-zeitalter-von-herbert-giersch-9783161527302?no_cache=1

order@mohrsiebeck.com

Telefon: +49 (0)7071-923-17

Telefax: +49 (0)7071-51104 